\title{
Calcium-Modulated Guanylate Cyclase Transduction Machinery in the Photoreceptor-Bipolar Synaptic Region ${ }^{\dagger}$
}

\author{
Venkateswar Venkataraman, ${ }^{\ddagger}$ Teresa Duda, ${ }^{\ddagger}$ Noga Vardi, ${ }^{\S}$ Karl-Wilhelm Koch,,$"$ and Rameshwar K. Sharma*, \\ The Unit of Regulatory and Molecular Biology, Departments of Cell Biology and Ophthalmology, New Jersey Medical School \\ and School of Osteopathic Medicine, University of Medicine and Dentistry of New Jersey, Stratford, New Jersey 08084, \\ Institut für Biologische Informationsverarbeitung-1, Forschungszentrum Jülich, D-52425 Jülich, Germany, and Department of \\ Neuroscience, University of Pennsylvania, Philadelphia, Pennsylvania 19104
}

Received January 8, 2003; Revised Manuscript Received March 25, 2003

\begin{abstract}
Rod outer segment membrane guanylate cyclase (ROS-GC) transduction system is a central component of the $\mathrm{Ca}^{2+}$-sensitive phototransduction machinery. The system is composed of two parts: $\mathrm{Ca}^{2+}$ sensor guanylate cyclase activating protein (GCAP) and ROS-GC. GCAP senses $\mathrm{Ca}^{2+}$ impulses and inhibits the cyclase. This operational feature of the cyclase is considered to be unique and exclusive in the phototransduction machinery. A combination of reconstitution, peptide competition, cross-linking, and immunocytochemical studies has been used in this study to show that the GCAP1/ROS-GC1 transduction system also exists in the photoreceptor synaptic (presynaptic) termini. Thus, the presence of this system and its linkage is not unique to the phototransduction machinery. A recent study has demonstrated that the photoreceptor-bipolar synaptic region also contains a $\mathrm{Ca}^{2+}{ }_{\text {-stimulated ROS-GC1 }}$ transduction system [Duda, T., et al. (2002) EMBO J. 21, 2547-2556]. In this case, $\mathrm{S} 100 \beta$ senses $\mathrm{Ca}^{2+}$ and stimulates the cyclase. The inhibitory and stimulatory $\mathrm{Ca}^{2+}$-modulated ROS-GC1 sites are distinct. These findings allow the formation of a new topographic model of ROS-GC1 transduction. In this model, the catalytic module of ROS-GC1 at its opposite ends is flanked by GCAP1 and S100 $\beta$ modules. GCAP1 senses the $\mathrm{Ca}^{2+}$ impulse and inhibits the catalytic module; $\mathrm{S} 100 \beta$ senses the impulse and stimulates the catalytic module. Thus, ROS-GC1 acts as a bimodal $\mathrm{Ca}^{2+}$ signal transduction switch in the photoreceptor bipolar synapse.
\end{abstract}

An important conceptual advancement is emerging in the membrane guanylate cyclase field. It predicts that the rod outer segment membrane guanylate cyclase (ROS-GC), ${ }^{1}$ a subfamily of membrane guanylate cyclases, is the universal transduction machinery for the $\mathrm{Ca}^{2+}$ impulses arising in the sensory neurons. According to the cellular environment, $\mathrm{Ca}^{2+}$ either inhibits the machinery or stimulates it (reviewed in ref 1 ). The former, and the first operational feature of the machinery, was established with studies of the photoreceptor cells in which the initial individual components of the transduction machinery were discovered (reviewed in refs 2 and 3). ROS-GC, native to PR-OS, the site of phototransduction, was purified (4-7), sequenced in part (7), and then cloned, based on the sequences of its four peptides (8). Its functional identity to the native ROS-GC was established by its $\mathrm{Ca}^{2+}$-dependent reconstitution; it mimicked the native

This study was supported by U.S. Public Health Service Grants EY 10828 and DC 005349 (R.K.S.) and HL 58151 (T.D.) and DFG Grant Ko948/5-3 (K.-W.K.).

* To whom correspondence should be addressed. Phone: (856) 5666977. Fax: (856) 566-7057. E-mail: sharmark@umdnj.edu.

University of Medicine and Dentistry of New Jersey.

$\S$ University of Pennsylvania.

"Forschungszentrum Jülich.

${ }^{1}$ Abbreviations: CNG, cyclic nucleotide-gated; ELISA, enzymelinked immunosorbent assay; GCAP, guanylate cyclase activating protein; GMP, guanosine monophosphate; OPL, outer plexiform layer; PR-OS, photoreceptor outer segments; ROS-GC, rod outer segment membrane guanylate cyclase. conditions of phototransduction (9), in which $\mathrm{Ca}^{2+}$ with a $K_{1 / 2}$ of $\sim 100 \mathrm{nM}$ inhibits the guanylate cyclase $(10,11)$. In these studies, the recombinant form of GCAP1 was used as a $\mathrm{Ca}^{2+}$ sensor (9). It was, thereby, established that the GCAP1/ROS-GC1 system is a $\mathrm{Ca}^{2+}$-sensitive component of the phototransduction machinery. The studies supported an earlier prediction that a membrane-bound guanylate cyclase operates by $\mathrm{Ca}^{2+}$ through a $\mathrm{Ca}^{2+}$-binding factor, whose identity at the time was unknown (12).

Phototransduction is a biochemical process, where the light signal generates an electrical signal (reviewed in refs 2 and $3)$. Two interlocked critical components of the process are $\mathrm{Ca}^{2+}$ and cyclic GMP (12-15). The photon captured by its receptor rhodopsin creates a decline in the level of cyclic GMP, which results in closure of the CNG channel, and hyperpolarization of the photoreceptor plasma membrane. Closure of CNG-gated channels prevents $\mathrm{Ca}^{2+}$ from entering the cell, but a continuous operation of a $\mathrm{Na}^{+} / \mathrm{Ca}^{2+}, \mathrm{K}^{+}-$ exchanger leads to a decrease in the intracellular $\mathrm{Ca}^{2+}$ concentration from $\sim 500 \mathrm{nM}$ in the dark-adapted photoreceptor cell to $<100 \mathrm{nM}$. This in turn causes the activation of ROS-GC. An increased level of synthesis of cyclic GMP, which is concomitant with inactivation of the phototransduction cascade, results in opening of the channel and, thereby, restoration of the dark current of the photoreceptors.

According to the current knowledge of the phototransduction field, ROS-GC exists in two forms: the original form 
(8), renamed ROS-GC1 [retGC1, GC-E $(16,17)]$, and ROSGC2 (18) [retGC2, GC-F $(17,19)]$. To date, the majority of the biochemical work has been focused on ROS-GC1. Functional GCAP exists in three forms: GCAP1-GCAP3 (11,20-22). Reconstitution studies with recombinant ROSGC1 indicate that it can sense changes in free $\mathrm{Ca}^{2+}$ concentrations through either of the two GCAPs, 1 or $2(9$, $23,24)$. Each GCAP binds with a specific module in ROS$\mathrm{GC} 1$, residing in the intracellular region of the cyclase ( 9 , 23, 25-27). In the current phototransduction model, GCAPs and ROS-GC1 form a regulatory unit in native PR-OS (reviewed in ref 2). GCAPs sense light-dependent $\mathrm{Ca}^{2+}$ fluctuations and, in turn, cause proportionate changes in ROS-GC1 activity. In this way, three pivotal components of phototransduction $\left(\mathrm{Ca}^{2+}\right.$, GCAPs, and ROS-GC1) are physiologically connected. In the dark phase, the free $\mathrm{Ca}^{2+}$ concentration is $500 \mathrm{nM}, \mathrm{Ca}^{2+}$ is bound to GCAP, and the cyclase is in its basal state. Increasing levels of photoillumination intensity cause graded decreases in the concentration of $\mathrm{Ca}^{2+}$. These cause concomitant increases in the cyclase activity, which, in turn, alter the cyclic GMP concentration in the photoreceptor cell.

To date, the GCAP-modulated $\mathrm{Ca}^{2+}$-signaling ROS-GC1 transduction system has been established in PR-OS as a sole constituent of the phototransduction machinery. This study expands the boundaries of this system. It unequivocally establishes that the GCAP1/ROS-GC1 transduction system also exists in the photoreceptor synaptic terminus where, like in PR-OS, the system is inhibited by $\mathrm{Ca}^{2+}$. Earlier studies have detected the presence of a ROS-GC, without distinguishing between ROS-GC1 and ROS-GC2, in retinal cells other than photoreceptors, including the synaptic layers (28, 29). Immunolocalization studies have also suggested that GCAP1 and GCAP2 are present in synaptic regions $(30,31)$. A more recent study has shown that the photoreceptorbipolar synaptic region also contains the $\mathrm{Ca}^{2+}$-stimulated ROS-GC1 transduction system (34). The system achieves the stimulatory feature via its $\mathrm{Ca}^{2+}$ sensor $\mathrm{S} 100 \beta$, whose target sites are specifically mapped to two short regions in the C-terminal domain of ROS-GC1 (34). These sites are distinct from the GCAP1-modulated sites $(25,34)$. On the basis of the findings that ROS-GC1 attains reciprocal, bimodal regulation through its defined $\mathrm{Ca}^{2+}$ sensor component and the component influences ROS-GC1 through its specified domain, a new topographic model of the ROSGC1 transduction system is proposed. The model contends that the catalytic module of ROS-GC1 is flanked by GCAP1 and $\mathrm{S} 100 \beta$ regulatory modules. GCAP1 senses the $\mathrm{Ca}^{2+}$ impulse and inhibits the catalytic module; $100 \beta$ senses the impulse and stimulates the catalytic module. Thus, ROS$\mathrm{GC} 1$ operates as a bimodal $\mathrm{Ca}^{2+}$ signal transduction switch, both stimulated and inhibited by $\mathrm{Ca}^{2+}$ sparks in the photoreceptor-bipolar synapse region. Together with similar earlier findings in the pinealocytes (35) and in the olfactory system $(36,37)$, this study suggests the universality and versatility of the $\mathrm{Ca}^{2+}$-dependent ROS-GC transduction machinery in sensory neurons. Furthermore, the findings indicate that the spatial environment and the microdomain structure of the machinery determine whether $\mathrm{Ca}^{2+}$ waves accelerate or retard it in the formation of cyclic GMP.

\section{EXPERIMENTAL PROCEDURES}

Antibodies. Characterization of highly specific antibodies raised against ROS-GC1 and GCAP1 has been described previously (35-37). After the specificity of the reaction had been established, the ROS-GC1 and GCAP1 antibodies were enriched by precipitating the immunoglobulin fraction using ammonium sulfate. The antibodies were finally purified on antigen-affinity columns. ELISA and Western blots were used to determine the titer of the enriched antibodies. A dilution of 1:5000 was generally used for colorimetric detection of the antigen on Western blots. A monoclonal antibody against $\mathrm{S} 100 \beta$ (clone $\mathrm{SH}-\mathrm{B} 1$ ) was purchased from Sigma, and the SV-2 antibody was from DBHSS.

Synthesis of Oligopeptides. The peptides corresponding to ROS-GC1 regions L503-I522, scrambled 503-522, D507R518, and G968-G985 were synthesized as described previously $(25,38)$.

Expression Studies. COS-7 cells (simian virus 40transformed African green monkey kidney cells), maintained in Dulbecco's modified Eagle's medium with penicillin, streptomycin, and $10 \%$ fetal bovine serum, were transfected with the wild type-recombinant (wt-r) ROS-GC1 expression construct by the calcium phosphate coprecipitation technique (39). Sixty hours after transfection, cells were washed twice with $50 \mathrm{mM}$ Tris- $\mathrm{HCl}(\mathrm{pH} 7.5)$ and $10 \mathrm{mM}$ buffer, scraped into $2 \mathrm{~mL}$ of cold buffer, homogenized, centrifuged for 15 $\min$ at $5000 \mathrm{~g}$, and washed several times with the same buffer. The resulting pellet represented crude membranes.

Preparation of the Retinal PI Fraction. The isolation of the P1 fraction from the bovine retina was carried out according to the originally published technique (40), and recently used in the analysis of the outer synaptic (P1) layer as described in ref 34 . The preparation was aliquoted and stored at $-150{ }^{\circ} \mathrm{C}$ until it was used.

Guanylate Cyclase Activity Assay. Membrane fractions were assayed for guanylate cyclase activity as described previously (41). Briefly, membranes were preincubated on an ice bath with or without GCAP1 or $\mathrm{S} 100 \beta$ in the assay system containing $10 \mathrm{mM}$ theophylline, $15 \mathrm{mM}$ phosphocreatine, $20 \mu \mathrm{g}$ of creatine kinase, and $50 \mathrm{mM}$ Tris- $\mathrm{HCl}(\mathrm{pH}$ 7.5) adjusted to the appropriate free $\mathrm{Ca}^{2+}$ concentrations with precalibrated $\mathrm{Ca}^{2+} /$ EGTA solutions (Molecular Probes). The total assay volume was $25 \mu \mathrm{L}$. The reaction was initiated by addition of the substrate solution containing $4 \mathrm{mM} \mathrm{MgCl} 2$ and $1 \mathrm{mM} \mathrm{GTP}$ and maintained by incubation at $37^{\circ} \mathrm{C}$ for $10 \mathrm{~min}$. The reaction was terminated by addition of $225 \mu \mathrm{L}$ of $50 \mathrm{mM}$ sodium acetate buffer ( $\mathrm{pH}$ 6.2) followed by heating in a boiling water bath for $3 \mathrm{~min}$. The amount of cyclic GMP that was formed was determined by a radio-immunoassay (42).

Peptide Competition Experiments. These were carried out with both native (PR-OS or P1) and recombinant (expressed in COS cells) ROS-GC1 $(4,11,34)$. Respective membranes were assayed for guanylate cyclase activity in the presence of $10 \mathrm{nM} \mathrm{Ca}^{2+}$ and $4 \mu \mathrm{M}$ GCAP1 with incremental concentrations of peptides.

Western Blot. Western blotting was carried out according to the previously published protocols $(35,37)$. Briefly, the protein samples were transferred onto nitrocellulose membranes after electrophoresis. The membranes were incubated in Tris-buffered saline containing $0.05 \%$ Tween 20 (TBS-T) and $3 \%$ bovine serum albumin (BSA) for $1 \mathrm{~h}$ at 
room temperature followed by incubation for $1 \mathrm{~h}$ in the same solution containing the primary antibody. After the membranes had been washed with TBS-T, incubation was continued for the same period of time in TBS-T containing $3 \%$ BSA and the secondary antibody. Then, visualization of the immunoreactive protein bands was carried out according to the manufacturer's (Vector labs) protocol.

Cross-Linking. Cross-linking was carried out with the imidoester dimethyl suberimidate (DMS $\cdot 2 \mathrm{HCl})$ on membranes isolated from the $\mathrm{P} 1$ fraction. This noncleavable crosslinker was chosen because it is water-soluble. One hundred micrograms of protein (with or without added recombinant GCAP1) was incubated at room temperature with shaking for $60 \mathrm{~min}$. The reaction was carried out in $0.2 \mathrm{M}$ triethanolamine $(\mathrm{pH}$ 8.0) in the presence of DMS concentrations ranging from 20 to $0.2 \mathrm{mM}$. It was terminated by the addition of Tris- $\mathrm{HCl}(\mathrm{pH} 6.8)$ to a final concentration of $100 \mathrm{mM}$, followed by the addition of SDS-PAGE loading dye. Samples were analyzed by SDS-PAGE (12 or 7\%), followed by transfer and Western blotting. Duplicates were probed independently with highly specific antibodies against ROSGC1 or GCAP1. Western blotting was carried out as described previously $(35,37)$.

Immunohistochemistry. Cryosections of the retina were prepared and used according to the procedure described previously (35). Briefly, the retina was fixed for $1 \mathrm{~h}$ in $4 \%$ formaldehyde at $4{ }^{\circ} \mathrm{C}$; it was cryoprotected in $25 \%$ sucrose overnight at $4{ }^{\circ} \mathrm{C}$ and cut in sections with a thickness of 16 $\mu \mathrm{m}$ (Leica cryostat). To block nonspecific protein binding, sections were incubated in $0.1 \mathrm{M}$ phosphate buffer containing $10 \%$ normal goat serum, $5 \%$ sucrose, and $0.5 \%$ Triton X-100 for $60 \mathrm{~min}$ at room temperature. The sections were then incubated in the same solution containing primary antibodies overnight at $4{ }^{\circ} \mathrm{C}$, washed, and incubated with secondary antibodies conjugated to a fluorescent dye and diluted in the blocking solution. Washes were carried out at room temperature (three times for $10 \mathrm{~min}$ each) with $0.1 \mathrm{M}$ phosphate buffer containing 5\% sucrose. For detection of ROS-GC1 in the synaptic regions, the detergent was omitted from the buffer. Specimens were mounted using Vectashield mounting medium. Images were acquired using a confocal microscope (Leica). Digital images were processed using commercially available software (ImagePro Plus, Phase3 Imaging Systems and Adobe Photoshop). Controls included immunostaining reactions carried out under identical conditions except that either primary antibody was omitted or was replaced with preimmune serum. Staining was insignificant in either case.

\section{RESULTS}

\section{The P1 Membrane Fraction Contains a Membrane Guanylate Cyclase, which Exhibits a Biphasic Type of $\mathrm{Ca}^{2+}$ Modulation}

The P1 fraction from the bovine retina, comprising the outer plexiform layer (OPL), was isolated as described in Experimental Procedures. Incubation of the P1 membranes with incremental $\mathrm{Ca}^{2+}$ concentrations showed that the fraction contained a guanylate cyclase transduction system, which was either stimulated or inhibited depending on the free $\mathrm{Ca}^{2+}$ concentration (Figure 1). A range of $\mathrm{Ca}^{2+}$ concentrations from $10 \mathrm{nM}$ to $\sim 0.4 \mu \mathrm{M}$ caused a dosedependent decrease in the cyclase activity, while higher $\mathrm{Ca}^{2+}$

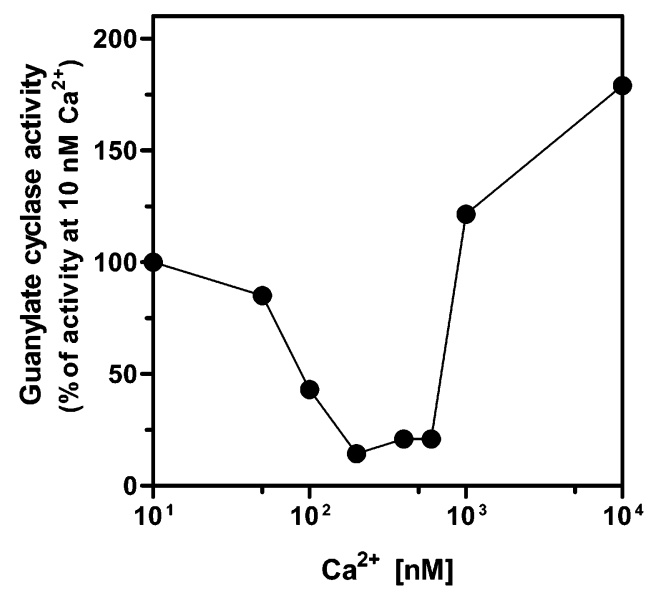

FIGURE 1: $\mathrm{Ca}^{2+}$ regulation of guanylate cyclase activity in membranes of the photoreceptor-bipolar cell synaptic layer (P1). The P1 fraction was prepared from the bovine retina as described in Experimental Procedures. These membranes were assayed for guanylate cyclase activity in the presence of incremental concentrations of $\mathrm{Ca}^{2+}$. Guanylate cyclase activity in the presence of $10 \mathrm{nM}$ $\mathrm{Ca}^{2+}$ was $0.9 \pm 0.1 \mathrm{nmol}$ of cyclic GMP (mg of protein $)^{-1} \mathrm{~min}^{-1}$. The experiments were carried out in triplicate and repeated three times with separate membrane preparations. The results are from one representative experiment.

concentrations caused a stimulation. The inhibitory value $\left(\mathrm{IC}_{50}\right)$ for $\mathrm{Ca}^{2+}$ was $100 \mathrm{nM}$, and the stimulatory value $\left(\mathrm{EC}_{50}\right)$ was $0.8 \mu \mathrm{M}$. The identity of the $\mathrm{Ca}^{2+}$-stimulated guanylate cyclase transduction system in the P1 membrane fraction has been reported recently (34). It consists of ROS-GC1 and its $\mathrm{Ca}^{2+}$ sensor component $\mathrm{S} 100 \beta$ (34). This raised a question about the identity of the $\mathrm{Ca}^{2+}$-inhibited membrane guanylate cyclase transduction system. This issue has been addressed below.

\section{The Ca ${ }^{2+}$-Inhibitory Transduction Component of the P1 Cyclase Is Represented by GCAPI/ROS-GCI}

To determine if the $\mathrm{Ca}^{2+}$-inhibited native $\mathrm{P} 1$ cyclase is similar to the phototransduction-linked ROS-GC, the P1 cyclase was subjected to multiple tests.

Test 1. The PR-OS and the P1 membrane fractions were isolated, and it was made certain that each does not cross contaminate the other (34). Side by side, these fractions were assayed for membrane guanylate cyclase activity in the presence of incremental $\mathrm{Ca}^{2+}$ concentrations, ranging from $10 \mathrm{nM}$ to $0.7 \mu \mathrm{M}$. The results presented in Figure 2 show that the cyclase activity in both fractions is incrementally inhibited. The inhibition patterns of the two fractions are almost identical; the $\mathrm{IC}_{50}$ for $\mathrm{Ca}^{2+}$ in both cases is $100 \mathrm{nM}$. Thus, the native $\mathrm{P} 1$ and the native PR-OS guanylate cyclases are functionally indistinguishable.

Test 2. Biochemical and functional similarities between the two native, P1 and PR-OS, guanylate cyclases were further established as follows. One sequence motif in ROS$\mathrm{GC} 1$ that is critical and specific for GCAP1 activation is between amino acids L503 and I522 (25). The core motif within this amino acid domain consists of D507-R518. To assess similarity (or dissimilarity) between the biochemical mechanisms involved in the functional $\mathrm{Ca}^{2+}$-inhibited guanylate cyclase machineries of the P1 and ROS-GC1 transduction systems, the P1 and PR-OS membrane fractions, side by side, were incubated with incremental concentrations of 


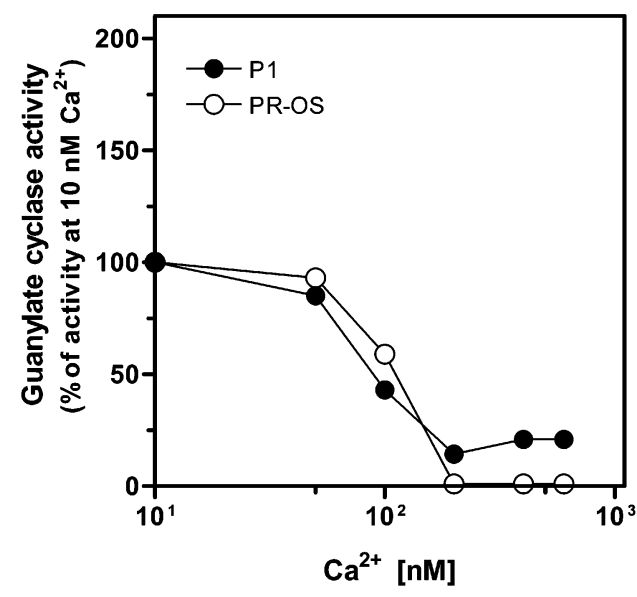

FIGURE 2: Effect of $\mathrm{Ca}^{2+}$ on guanylate cyclase activity in the P1 fraction and comparison with the effect of $\mathrm{Ca}^{2+}$ on the ROS-GC system present in the membrane fraction of photoreceptor outer segments. Membrane fractions from the P1 synaptosomal fraction (P1) and photoreceptor outer segments (PR-OS) were isolated as described in Experimental Procedures. These membranes were assayed for guanylate cyclase activity in the presence of incremental concentrations of $\mathrm{Ca}^{2+}$. Guanylate cyclase activities in the presence of $10 \mathrm{nM} \mathrm{Ca}^{2+}$ were $0.9 \pm 0.1 \mathrm{nmol}$ of cyclic GMP (mg of protein $)^{-1} \mathrm{~min}^{-1}$ for the $\mathrm{P} 1$ fraction and $9.0 \pm 0.5 \mathrm{nmol}$ of cyclic GMP (mg of protein) ${ }^{-1} \mathrm{~min}^{-1}$ for the PR-OS fraction. The experiments were carried out in triplicate and repeated three times with separate membrane preparations. The results are from one representative experiment.

the L503-I522 and D507-R518 peptides at $10 \mathrm{nM} \mathrm{Ca}^{2+}$. A peptide with the scrambled sequence of L503-I522 constituted a control. The results demonstrated a dosedependent inhibition, reaching $\sim 65 \%$ for the L503-I522 peptide and $\sim 83 \%$ for the D507-R518 peptide in both the $\mathrm{P} 1$ and PR-OS fractions (Figure 3). The scrambled peptide, at concentrations of up to $0.25 \mathrm{mM}$, in both fractions only minimally $(\sim 5-15 \%)$ inhibited the cyclase; at a concentration of $0.5 \mathrm{mM}$, the extent of inhibition was $\sim 20-30 \%$ (Figure 3). Furthermore, in both fractions, there was a reversal of the peptide (D507-R518)-dependent inhibition when an excess of GCAP1 was added (Figure 3C,D). These peptide competition and GCAP1 reconstitution results demonstrate that the $\mathrm{Ca}^{2+}$-inhibited modulation of the cyclases in the P1 and PR-OS membrane fractions occurs by identical mechanisms, in which the modulation is mediated by GCAP1 and the modulated cyclase in both cases is the same, ROSGC1. Hence, the operational biochemical components of the native P1 and PR-OS cyclase machineries are identical, and they are represented by GCAP1/ROS-GC1 transduction systems.

Test 3 . The conclusions from test 2 were further confirmed by reconstitution experiments using recombinant ROS-GC1 and GCAP1. The recombinant ROS-GC1 was expressed in the heterologous COS cell system. At $50 \mathrm{nM} \mathrm{Ca}^{2+}$, recombinant GCAP1 stimulated ROS-GC1 in a dose-dependent fashion with an $\mathrm{EC}_{50}$ of $1 \mu \mathrm{M}$. The maximal stimulation of the enzyme was achieved at $4 \mu \mathrm{M}$ GCAP1 (Figure $4 \mathrm{~A}$ ). The D507-R518 peptide inhibited the cyclase in a concentrationdependent fashion. The kinetics of inhibition of the recombinant ROS-GC1 were nearly identical to those of the cyclase present in the native P1 and PR-OS membrane fractions (compare Figure 4B with panels A and B of Figure 3). The control peptide, with a scrambled D507-R518 sequence,
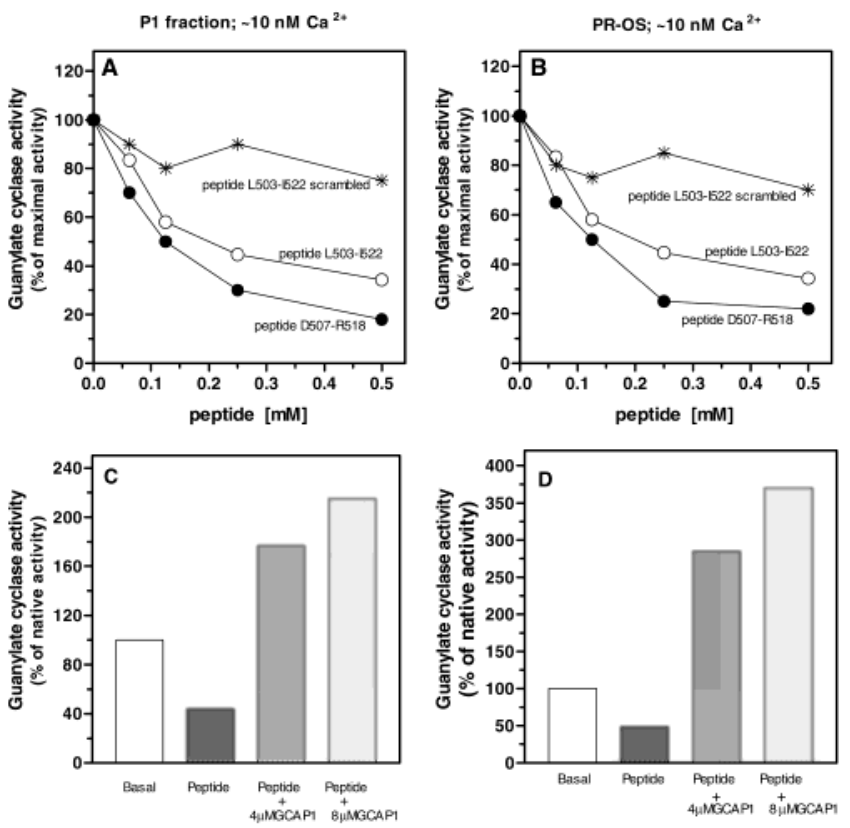

FIGURE 3: Effect of synthetic peptides derived from the ROS-GC1 sequence on GCAP1-dependent stimulation of ROS-GC1 activity. Membranes of P1 (A) or PR-OS (B) fractions were reconstituted with $2 \mu \mathrm{M}$ GCAP1 and $10 \mathrm{nM} \mathrm{Ca}^{2+}$ and incubated with the indicated peptide concentrations. Membranes of P1 (C) or PR-OS (D) fractions were incubated with $2 \mu \mathrm{M}$ GCAP1 and $250 \mu \mathrm{M}$ D507-R518 peptide at $10 \mathrm{nM} \mathrm{Ca}^{2+}$ with or without the indicated concentrations of GCAP1. The experiment was carried out in triplicate and repeated three times for reproducibility. The results are from one typical experiment. Error bars are within the size of the symbols.
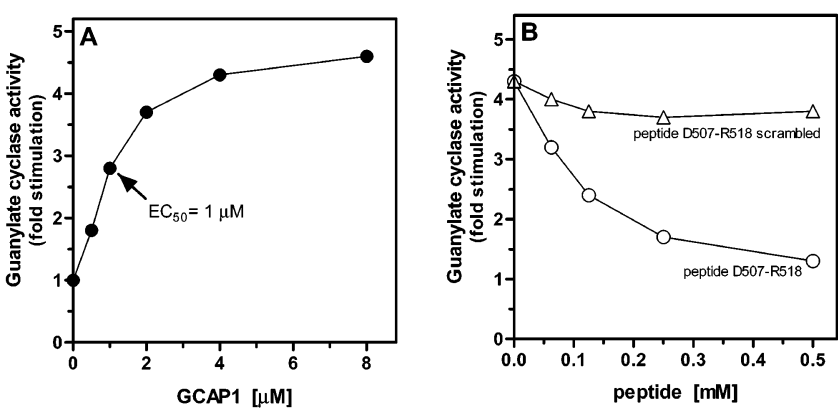

FIGURE 4: Dose-dependent response of recombinant ROS-GC1 to GCAP1 and the effect of synthetic D507-R518 and scrambled D507-R518 peptides. Membranes of COS cells expressing ROSGC1 were used. (A) They were reconstituted with the indicated concentrations of GCAP1 and $10 \mathrm{nM} \mathrm{Ca}^{2+}$. (B) They were incubated with $2 \mu \mathrm{M}$ GCAP1 and increasing concentrations of either peptide at $10 \mathrm{nM} \mathrm{Ca}^{2+}$. Experiments were carried out in triplicate and repeated at least two times for reproducibility. The data are from a representative experiment.

only very minimally inhibited ROS-GC1. These results validate the conclusions of test 2 and further show the direct participation of ROS-GC1 in GCAP1-mediated $\mathrm{Ca}^{2+}$ signal transduction in the $\mathrm{P} 1$ membrane fraction.

Test 4 . The aim of this test was to directly establish the presence of GCAP1 in the P1 membrane fraction. Western blot analysis of the fraction was performed with the GCAP1specific antibody according to a previous protocol (35). It is noted that this antibody has an absolute specificity for GCAP1 and does not react with the other member, GCAP2 (Figure 5A, compare rGCAP1 and rGCAP2). Purified PR-OS membrane preparations (PR-OS lane) and recombi- 
A RETINA rGCAP1 rGCAP2

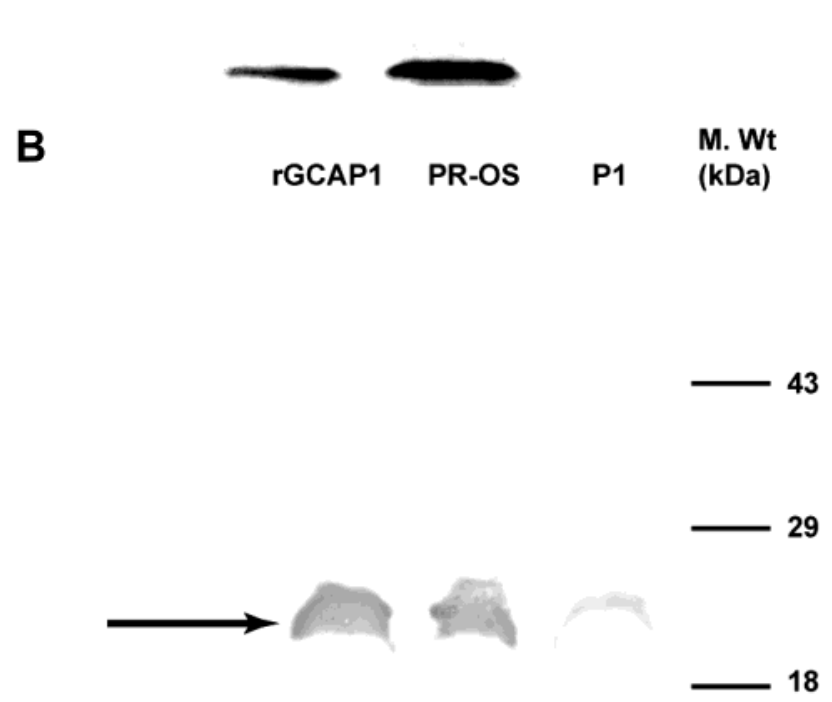

FIGURE 5: Presence of GCAP1 in the membranes of the P1 fraction and immunological analyses with the GCAP1-specific antibody. (A) Specificity of the GCAP1 antibody. Bacterially expressed and purified GCAP1 (rGCAP1), GCAP2 expressed in insect cells and purified (rGCAP2), and membranes from retina (RETINA) were electrophoresed and analyzed by Western blotting. (B) GCAP1 expression in the $\mathrm{P} 1$ fraction. Membranes of the $\mathrm{P} 1$ fraction were isolated and analyzed by Western blotting as described in Experimental Procedures. Fifty micrograms of the membrane protein was loaded in the PR-OS and P1 lanes; $0.5 \mu \mathrm{g}$ of recombinant GCAP1 (rGCAP1) served as a control. Molecular size markers are given.

nant GCAP1 (rGCAP1 lane) served as positive controls. A single $21 \mathrm{kDa}$ GCAP1 immunoreactive band, indicated with an arrow, with identical mobility was detected in each case (Figure 5B, compare rGCAP1, PR-OS, and P1). Thus, the native P1 fraction contains GCAP1.

Through four independent criteria, it is concluded that the P1 membrane fraction contains the GCAP1-modulated $\mathrm{Ca}^{2+}$ inhibited ROS-GC1 transduction system and the system is functionally and biochemically identical to the one linked with the phototransduction machinery.

\section{Cross-Linking Analysis Reveals that GCAP1 and ROS-GCl Reside in Proximity in the Retinal Pl Fraction}

To be physiologically relevant, GCAP1 and ROS-GC1 must reside in proximity. This was determined by crosslinking studies. The noncleavable imidoester DMS was used as a cross-linker. The reaction and analysis were carried out as described in Experimental Procedures, and the results are presented in Figure 6. Without the cross-linker, the ROSGC1 antibody identified only the ROS-GC1 monomer and the GCAP1 antibody the GCAP1 monomer. In the presence of the cross-linker, both GCAP1 and ROS-GC1 antibodies identified a common immunoreactive band at $\sim 250 \mathrm{kDa}$ (indicated by a double-headed arrow). The size is that expected for a ROS-GC1 dimer-GCAP1 complex. The band was absent when the cross-linker was omitted (compare + lanes vs - lanes in GCAP1 and ROS-GC1). The mobility of the cross-linked complex suggests that the predominant interaction between ROS-GC1 and GCAP1 occurs in their dimeric forms. In reactions with the ROS-GC1 antibody, an immunoreactive band at $\sim 120 \mathrm{kDa}$ is seen and corresponds

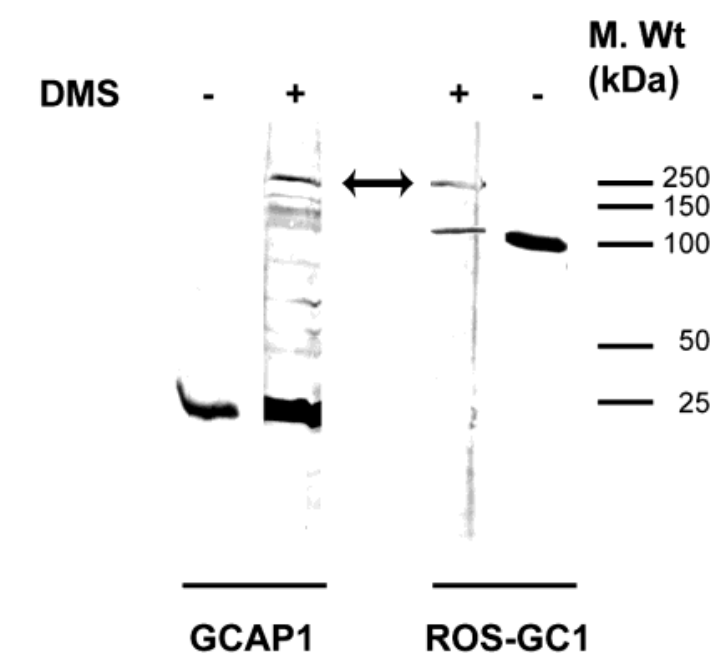

FIGURE 6: ROS-GC1 and GCAP1 are in proximity in the P1 fraction. The gel shows a cross-linking analysis. Membranes of the $\mathrm{P} 1$ fraction were isolated and incubated in the presence or absence of added GCAP1 $(1 \mu \mathrm{M})$ with or without the cross-linker DMS. Cross-linking was carried out as described in Experimental Procedures. The reaction was terminated by boiling in SDS-PAGE loading buffer. Duplicate samples were electrophoresed on SDS$6 \%$ polyacrylamide gels and analyzed by Western blotting with ROS-GC1 or GCAP1 antibody. Similar results were obtained in the presence or absence of added GCAP1, except that the band intensities were enhanced in the presence of GCAP1. The results, with added GCAP1, are presented in the respective panels; a 100 $\mu \mathrm{g}$ equivalent of membrane protein was loaded in each lane. A common band, corresponding to $\sim 250 \mathrm{kDa}$, is observed with both antibodies in the presence of the cross-linker ( + lanes) and is denoted with a double-headed arrow. Only the monomers of GCAP1 and ROS-GC1 are observed in the absence of the crosslinker ( - lanes). Molecular size markers are given.

to the ROS-GC1 monomer (Figure 6, both lanes, ROS-GC1 panel). In reactions with the GCAP1 antibody, an immunoreactive band corresponding to the GCAP1 monomer is detected (Figure 6, both lanes, GCAP1 panel). Several additional bands are observed with the GCAP1 antibody probe in the presence of the cross-linker (Figure $6,+$ lane, GCAP1 panel), indicating that this protein may interact with several proteins other than ROS-GC1 in the retinal P1 layer. The results show that ROS-GC1 and GCAP1 reside in proximity in the retinal $\mathrm{P} 1$ fraction.

\section{ROS-GC1 and GCAP1 Colocalize in Cone Synaptic Termini}

To determine if ROS-GC1 and GCAP1 are localized in the outer plexiform layer, which is concentrated in the P1 fraction, immunolocalization of the two proteins was carried out on serial cryosections of the retina. Staining for ROSGC1 was intense in both the rod and cone outer segments (Figure 7B). This is in agreement with the conclusion that the cyclase is expressed in both photoreceptor outer segments based on biochemical and genetic analyses (4, 5, 43-45). Staining was also observed in the inner segments, particularly those of cones. When Triton X-100 was excluded from the incubation medium, staining for the outer segment was still present; in addition, staining was also observed in the OPL and a weaker staining in the inner plexiform layer (IPL, Figure 7C). Under both conditions (with and without detergent), preadsorption of the antibody with the antigen eliminated the staining (data not shown). 

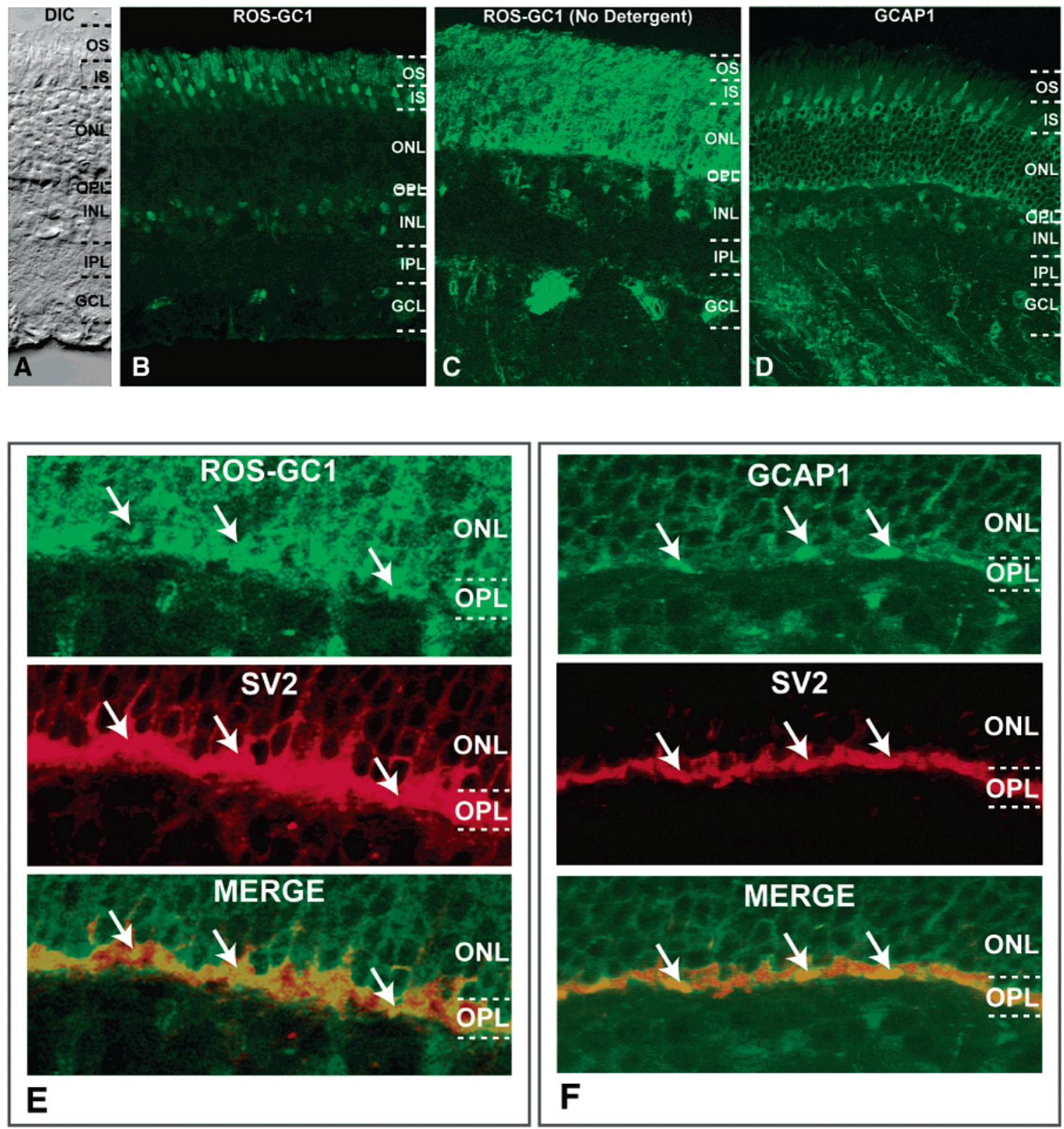

FIGURE 7: ROS-GC1 and GCAP1 are colocalized in cone synaptic termini. Radial cryosections of bovine retina were immunostained for ROS-GC1 and GCAP1. (A) Differential interference contrast (DIC) image of a retinal section showing the retinal layers. (B) Distribution of ROS-GC1 as revealed by staining with the standard protocol. Staining is strong in rod and cone outer segments but is also present in other cells in the INL and GCL. (C) Distribution of ROS-GC1 as revealed by omitting Triton X-100. Staining is more ubiquitous, and is strong in the OPL. (D) Distribution of GCAP. Staining is strong in cone outer and inner segments and in the OPL. (E) Double staining for ROS-GC1 and SV2 (in the absence of the detergent Triton X-100). Certain OPL structures stained for SV2 (red) are also stained for ROS-GC1 (green); these appear orange-yellow in the MERGE panel. Some are denoted with arrows. The lack of total colocalization may be due to limited penetration in the ROS-GC1 staining. (F) Double staining for GCAP1 and SV2. All GCAP1-positive (green) structures in the OPL are also stained for SV2 (red) and appear orange-yellow in the MERGE panel. Some are denoted with arrows. Abbreviations: OS, outer segments; ONL, outer nuclear layer; OPL, outer plexiform layer; INL, inner nuclear layer; IPL, inner plexiform layer; GCL, ganglion cell layer. The boundaries of the different layers have been denoted with dashed lines.

Positive staining for GCAP1 is observed in the outer segments, inner segments, outer nuclear layer, and outer plexiform layer (Figure 7D). In the outer and inner segment layers, predominant staining was observed in the cone inner and outer segments. These observations are consistent with those from earlier studies $(10,11,30-33)$. In the OPL, staining was in large structures, from which axons were ascending through the ONL to the inner segments. These are likely cone synaptic termini.

To determine which structures within the OPL are stained, the sections were doubly labeled with the antibodies against
GCAP1 or ROS-GC1 and SV2, a synaptic vesicle protein that strongly stains photoreceptor termini (46). At higher magnification, colocalization of ROS-GC1 (in green) and SV2 (in red) is seen throughout the OPL, suggesting that ROS-GC1 is expressed in photoreceptor termini (Figure 7E). Some photoreceptor termini are indicated with arrows. The colocalization of GCAP1 with SV2 is presented in Figure 7F. Staining for GCAP1 is strong in the OPL, and it colocalizes with SV2, confirming that the GCAP1-positive structures in the OPL are cone synaptic termini. Because both ROS-GC1 and GCAP1 are localized to cone synaptic 
termini, results from immunostaining, together with biochemical and cross-linking analyses, establish that these two proteins are coexpressed not only in the cone outer segment but also in the cone synaptic terminus, which is presynaptic to the bipolar neurons.

\section{DISCUSSION}

To date, the physiologically relevant GCAP-mediated $\mathrm{Ca}^{2+}$ signaling has only been found in photoreceptor outer segments. There it regulates the activity of the membranebound guanylate cyclase ROS-GC1 and is a critical part of a negative feedback loop that defines the recovery of a photoreceptor's light response. GCAPs sense changes in the $\mathrm{Ca}^{2+}$ concentration and undergo a conformational change. The change triggers activation of ROS-GC1 at low $\mathrm{Ca}^{2+}$ concentrations and inhibition of ROS-GC1 at high $\mathrm{Ca}^{2+}$ concentrations. This study provides comprehensive biochemical and immunological evidence to show that GCAP1mediated $\mathrm{Ca}^{2+}$ signaling is also present in the presynaptic region of the photoreceptor cells, and it colocalizes with ROS-GC1.

In a recent report, Duda et al. (34) showed that ROS-GC1 with its $\mathrm{Ca}^{2+}$ sensor $\mathrm{S} 100 \beta$ is present in the photoreceptorbipolar synaptic layer, and in this layer, $\mathrm{Ca}^{2+}$ stimulates ROSGC1. It is, thus, concluded that the outer synaptic layer is an area of extreme sensitivity to $\mathrm{Ca}^{2+}$ waves and that the waves are sensed by either GCAP1 or $\mathrm{S} 100 \beta$, which, in turn, stimulates or inhibits ROS-GC1. The study presented here establishes the presynaptic localization of the GCAP1/ROSGC1 transduction system. Whether the S100 $\beta /$ ROS-GC1 transduction system is presynaptic, postsynaptic, or both remains to be investigated. In addition to GCAP1 and $\mathrm{S} 100 \beta$, ROS-GC1 is also modulated by GCAP2 (reviewed in refs 1 and 2). The current evidence indicates that GCAP2 is also present in the retinal synaptic layers $(30-32)$, creating the possibility that the GCAP2/ROS-GC1 system may also be functional. This possibility also remains to be investigated.

At the moment, one can only speculate about how the GCAP1/ROS-GC1 system is linked to other signaling components in the presynaptic region of photoreceptors. A possible target of cyclic GMP could be a CNG channel in synaptic termini of cones $(47,48)$. Activation of these channels triggers release of glutamate from the terminus. The GCAP1/ROS-GC1 system could provide a $\mathrm{Ca}^{2+}$-dependent negative feedback control of $\mathrm{CNG}$ channels. When the $\mathrm{Ca}^{2+}$ influx via voltage-dependent $\mathrm{Ca}^{2+}$ channels stops (for example, during hyperpolarization), the free $\mathrm{Ca}^{2+}$ concentration in synaptic termini would transiently decrease and in turn activate the GCAP1/ROS-GC1 system. It has been recently shown that $\mathrm{Ca}^{2+}$ levels fluctuate over a 10-fold range in photoreceptor synapses and reach values as low as $50 \mathrm{nM}$ (reviewed in ref 49), where the GCAP1/ROS-GC1 system is, indeed, most effective. An increase in the level of cyclic GMP would open the CNG channels, and an influx of $\mathrm{Ca}^{2+}$ would dampen the GCAP1/ROS-GC1 system. The CNG channels in cone synaptic termini appear to be influenced also by nitric oxide, which can activate the soluble form of a guanylate cyclase present in inner segments of photoreceptors (50). Thus, the complexity of cyclic GMP signaling in synaptic regions points to several spatially and temporarily restricted events and needs to be worked out in more detail.
Recent investigations have documented the presence of a $\mathrm{Ca}^{2+}$-modulated membrane guanylate cyclase transduction system in three neuronal systems besides visual transduction: the pinealocytes, the cilia of the olfactory neuroepithelium, and the olfactory bulb $(35-37)$. Like the photoreceptors, the pineal gland is modulated by light. The ciliated apical border of sensory neurons located in the epithelial layer is the site of odorant transduction. And, the olfactory bulb is the second neural compartment where the odorant signal is processed and is then transmitted to the olfactory cortex for smell perception. $\mathrm{Ca}^{2+}$-regulated membrane guanylate cyclase resides in all three neural systems (35-37). One class of the pinealocytes contains the GCAP1/ROS-GC1 transduction system, and the second class contains the S100 $\beta$ / ROS-GC1 transduction system (35). The olfactory cilia contain the neurocalcin/ONE-GC [also known as GC-D (51)] transduction system (36), and the olfactory bulb contains the GCAP1/ROS-GC1 transduction system (37). Thus, native functional expression of ROS-GC1 is not restricted to outer segments of photoreceptor cells, and its expression may be a common feature of neurons linked with sensory perception. Its regulatory features are rather complex and depend on the specific cellular or subcellular localization.

The different modulatory features of ROS-GC1 are possible through the presence of regulatory and/or target regions in distant domains of the protein. Like other members of the membrane guanylate cyclase family, ROS-GC1 is a modular protein with the following common topography. A single helical transmembrane domain divides the protein into two portions. The $\mathrm{N}$-terminus consists of an extracellular domain or intradiscal domain when present in PR-OS. The intracellular region is comprised of a juxtamembrane domain, a kinase homology domain, a dimerization domain, and a core catalytic domain. The guanylate cyclase family is subdivided into two subfamilies: the peptide hormone receptor and the $\mathrm{Ca}^{2+}$-modulated ROS-GC (reviewed in ref 1). The extracellular domain of the peptide hormone receptor subfamily contains the receptor domain. To date, in the ROSGC subfamily, neither a ligand for nor the functional relevance of this domain has been found. As a functional unit, it is believed that all membrane guanylate cyclases exist as homodimers (reviewed in ref 1). The ROS-GC subfamily contains an added segment at its C-terminus, which is not shared with the peptide receptor subfamily (reviewed in refs 1 and 2). This has been termed the C-terminal extension. A recent study has shown that the $\mathrm{C}$-terminal extension is the site of the $\mathrm{S} 100 \beta$-modulated domain in ROS-GC1, and this domain regulates the catalytic activity of the cyclase (34). This domain has been mapped to two small regions: one region comprises amino acids (aa) G962-N981 and the other aa I1030-Q1041. The GCAP1-modulated domain resides at two regions, M445-L456 and L503-I522, in the juxtamembrane domain (25). The domain is physiologically linked with the GCAP1-modulated activity, because a point mutation in this domain causes Leber's congenital amaurosis and loss of GCAP1-dependent ROS-GC1 regulation (44). Two other GCAP1 binding regions have also been reported, and they also reside at the N-terminal side of the catalytic domain; however, these regions have not been physiologically linked with GCAP1 regulation (25). Thus, the GCAP1regulated module resides at the $\mathrm{N}$-terminal side of the catalytic module and the $\mathrm{S} 100 \beta$-regulated module at its 


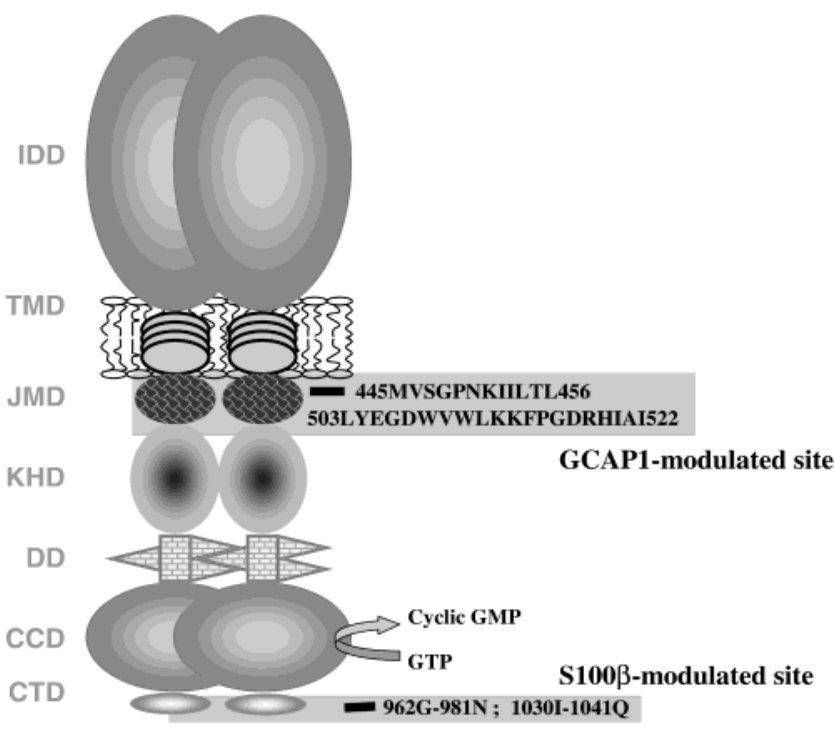

FIGURE 8: Modular domain topography of ROS-GC1. The GCAP1 and $\mathrm{S} 100 \beta$ modulated domains are indicated. Abbreviations: IDD, intradiscal domain; TMD, transmembrane domain; JMD, juxtamembrane domain; KHD, kinase homology domain; DD, dimerization domain; CCD, catalytic cyclase domain; CTD, C-terminal domain.

C-terminal side, and the two modules independently regulate the catalytic module. These findings allow the formation of a new topographic model of ROS-GC1 transduction (Figure 8). In this model, the catalytic module of ROS-GC1 at its opposite ends is flanked by GCAP1 and $\mathrm{S} 100 \beta$ modules. GCAP1 senses the $\mathrm{Ca}^{2+}$ impulse and inhibits the catalytic module; S100 $\beta$ senses the impulse and stimulates the catalytic module. In this manner, ROS-GC1 acts as a bimodal $\mathrm{Ca}^{2+}$ signal transduction switch in sensory neurons. The model defines reciprocal regulation of ROS-GC1 by $\mathrm{Ca}^{2+}$ in biochemical terms. Finally, the location of the high $\mathrm{Ca}^{2+}$ regulated domain in the $\mathrm{C}$-terminal extension may constitute a signature feature of the ROS-GC subfamily of membrane guanylate cyclases.

\section{ACKNOWLEDGMENT}

We thank Marie Fina for technical assistance and Joan Sharma for editorial assistance.

\section{REFERENCES}

1. Sharma, R. K. (2002) Evolution of the membrane guanylate cyclase transduction system, Mol. Cell. Biochem. 230, 3-30.

2. Koch, K.-W., Duda, T., and Sharma, R. K. (2002) Photoreceptor specific guanylate cyclases in vertebrate phototransduction, $\mathrm{Mol}$. Cell. Biochem. 230, 97-106.

3. Pugh, E. N., Jr., Duda, T., Sitaramayya, A., and Sharma, R. K. (1997) Photoreceptor guanylate cyclases: a review, Biosci. Rep. 17, 429-473.

4. Koch, K.-W. (1991) Purification and identification of photoreceptor guanylate cyclase, J. Biol. Chem. 266, 8634-8637.

5. Hayashi, F., and Yamazaki, A. (1991) Polymorphism in purified guanylate cyclase from vertebrate rod photoreceptors, Proc. Natl. Acad. Sci. U.S.A. 88, 4746-4750.

6. Aparicio, J. G., and Applebury, M. L. (1995) The bovine photoreceptor outer segment guanylate cyclase: purification, kinetic properties, and molecular size, Protein Expression Purif. 6, 501-511.

7. Margulis, A., Goraczniak, R. M., Duda, T., Sharma, R. K., and Sitaramayya, A. (1993) Structural and biochemical identity of retinal rod outer segment membrane guanylate cyclase, Biochem. Biophys. Res. Commun. 194, 855-861.
8. Goraczniak, R. M., Duda, T., Sitaramayya, A., and Sharma, R. K. (1994) Structural and functional characterization of the rod outer segment membrane guanylate cyclase, Biochem. J. 302, $455-461$.

9. Duda, T., Goraczniak, R. M., Surgucheva, I., Rudnicka-Nawrot, M., Gorczyca, W. A., Palczewski, K., Baehr, W., and Sharma, R. K. (1996) Calcium modulation of bovine photoreceptor guanylate cyclase, Biochemistry 35, 8478-8482.

10. Gorczyca, W. A., Polans, A. S., Surgucheva, I. G., Subbaraya, I., Baehr, W., and Palczewski, K. (1995) Guanylyl cyclase activating protein. A calcium-sensitive regulator of phototransduction, J. Biol. Chem. 270, 22029-22036.

11. Frins, S., Bonigk, W., Muller, F., Kellner, R., and Koch, K.-W. (1996) Functional characterization of a guanylyl cyclase-activating protein from vertebrate rods. Cloning, heterologous expression, and localization, J. Biol. Chem. 271, 8022-8027.

12. Koch, K.-W., and Stryer, L. (1988) Highly cooperative feedback control of retinal rod guanylate cyclase by calcium ions, Nature 334, 64-66.

13. Gray-Keller, M. P., and Detwiler, P. B. (1994) The calcium feedback signal in the phototransduction cascade of vertebrate rods, Neuron 13, 849-861.

14. Korenbrot, J. I., and Miller, D. L. (1989) Cytoplasmic free calcium concentration in dark-adapted retinal rod outer segments, Vision Res. 29, 939-948.

15. Koutalos, Y., and Yau, K.-W. (1996) Regulation of sensitivity in vertebrate rod photoreceptors by calcium, Trends Neurosci. 19 , 73-81.

16. Shyjan, A. W., de Sauvage, F. J., Gillett, N. A., Goeddel, D. V., and Lowe, D. G. (1992) Molecular cloning of a retina-specific membrane guanylyl cyclase, Neuron 9, 727-737.

17. Yang, R. B., Foster, D. C., Garbers, D. L., and Fulle, H. J. (1995) Two membrane forms of guanylyl cyclase found in the eye, Proc. Natl. Acad. Sci. U.S.A. 92, 602-606.

18. Goraczniak, R. M., Duda, T., and Sharma, R. K. (1998) Calcium modulated signaling site in type 2 rod outer segment membrane guanylate cyclase (ROS-GC2), Biochem. Biophys. Res. Commun. 245, 447-453.

19. Lowe, D. G., Dizhoor, A. M., Liu, K., Gu, Q., Spencer, M., Laura, R., Lu, L., and Hurley, J. B. (1995) Cloning and expression of a second photoreceptor-specific membrane retina guanylyl cyclase (RetGC), RetGC-2, Proc. Natl. Acad. Sci. U.S.A. 92, 5535-5539.

20. Dizhoor, A. M., Olshevskaya, E. V., Henzel, W. J., Wong, S. C., Stults, J. T., Ankoudinova, I., and Hurley, J. B. (1995) Cloning, sequencing, and expression of a $24-\mathrm{kDa} \mathrm{Ca}^{2+}$-binding protein activating photoreceptor guanylyl cyclase, J. Biol. Chem. 270, 25200-25206.

21. Gorczyca, W. A., Gray-Keller, M. P., Detwiler, P. B., and Palczewski, K. (1994) Purification and physiological evaluation of a guanylate cyclase activating protein from retinal rods, Proc. Natl. Acad. Sci. U.S.A. 91, 4014-4018.

22. Haeseleer, F., Sokal, I., Li, N., Pettenati, M., Rao, N., Bronson, D., Wechter, R., Baehr, W., and Palczewski, K. (1999) Molecular characterization of a third member of the guanylyl cyclaseactivating protein subfamily, J. Biol. Chem. 274, 6525-6535.

23. Krishnan, A., Goraczniak, R. M., Duda, T., and Sharma, R. K. (1998) Third calcium-modulated rod outer segment membrane guanylate cyclase transduction mechanism, Mol. Cell. Biochem. 178, 251-259.

24. Dizhoor, A. M., and Hurley, J. B. (1999) Regulation of photoreceptor membrane guanylyl cyclases by guanylyl cyclase activator proteins, Methods 19, 521-531.

25. Lange, C., Duda, T., Beyermann, M., Sharma, R. K., and Koch, K.-W. (1999) Regions in vertebrate photoreceptor guanylyl cyclase ROS-GC1 involved in $\mathrm{Ca}^{2+}$-dependent regulation by guanylyl cyclase-activating protein GCAP-1, FEBS Lett. 460, 27-31.

26. Sokal, I., Haeseleer, F., Arendt, A., Adman, E. T., Hargrave, P. A., and Palczewski, K. (1999) Identification of a guanylyl cyclaseactivating protein-binding site within the catalytic domain of retinal guanylyl cyclase 1, Biochemistry 38, 1387-1393.

27. Krylov, D. M., and Hurley, J. B. (2001) Identification of proximate regions in a complex of retinal guanylyl cyclase 1 and guanylyl cyclase-activating protein-1 by a novel mass spectrometry-based method, J. Biol. Chem. 276, 30648-30654.

28. Liu, X., Seno, K., Nishizawa, Y., Hayashi, F., Yamazaki, A., Matsumoto, H., Wakabayashi, T., and Usukura, J. (1994) Ultra- 
structural localization of retinal guanylate cyclase in human and monkey retinas, Exp. Eye Res. 59, 761-768.

29. Cooper, N., Liu, L., Yoshida, A., Pozdnyakov, N., Margulis, A., and Sitaramayya, A. (1995) The bovine rod outer segment guanylate cyclase, ROS-GC, is present in both outer segment and synaptic layers of the retina, J. Mol. Neurosci. 6, 211-222.

30. Cuenca, N., Lopez, S., Howes, K., and Kolb, H. (1998) The localization of guanylyl cyclase-activating proteins in the mammalian retina, Invest. Ophthalmol. Visual Sci. 39, 1249-1250.

31. Kachi, S., Nishizawa, Y., Olshevskaya, E., Yamazaki, A., Miyake, Y., Wakabayashi, T., Dizhoor, A., and Usukura, J. (1999) Detailed localization of photoreceptor guanylate cyclase activating protein-1 and -2 in mammalian retinas using light and electron microscopy, Exp. Eye Res. 68, 465-473.

32. Howes, K., Bronson, J. D., Dang, Y. L., Li, N., Zhang, K., Ruiz, C., Helekar, B., Lee, M., Subbaraya, I., Kolb, H., Chen, J., and Baehr, W. (1998) Gene array and expression of mouse retina guanylate cyclase activating proteins 1 and 2, Invest. Ophthalmol. Visual Sci. 39, 867-875.

33. Muller, F., and Koch, K.-W. (1998) Calcium-binding proteins and nitric oxide in retinal function and disease, Acta Anat. 162, 142150.

34. Duda, T., Koch, K.-W., Venkataraman, V., Lange, C., Beyermann, M., and Sharma, R. K. (2002) $\mathrm{Ca}^{2+}$ sensor S100 $\beta$-modulated sites of membrane guanylate cyclase in the photoreceptor-bipolar synapse, EMBO J. 21, 2547-2556.

35. Venkataraman, V., Nagele, R., Duda, T., and Sharma, R. K. (2000) Rod outer segment membrane guanylate cyclase type 1-linked stimulatory and inhibitory calcium signaling systems in the pineal gland: biochemical, molecular, and immunohistochemical evidence, Biochemistry 39, 6042-6052.

36. Duda, T., Jankowska, A., Venkataraman, V., Nagele, R. G., and Sharma, R. K. (2001) A novel calcium-regulated membrane guanylate cyclase transduction system in the olfactory neuroepithelium, Biochemistry 40, 12067-12077.

37. Duda, T., Venkataraman, V., Krishnan, A., Nagele, R. G., and Sharma, R. K. (2001) Negatively calcium-modulated membrane guanylate cyclase signaling system in the rat olfactory bulb, Biochemistry 40, 4654-4662.

38. Schrem, A., Lange, C., Beyermann, M., and Koch, K.-W. (1999) Identification of a domain in guanylyl cyclase-activating protein 1 that interacts with a complex of guanylyl cyclase and tubulin in photoreceptors, J. Biol. Chem. 274, 6244-6249.

39. Sambrook, M. J., Fritsch, E. F., and Maniatis, T. (1989) Molecular Cloning: A Laboratory Manual, Cold Spring Harbor Laboratory Press, Plainview, NY.
40. Redburn, D. A., and Thomas, T. N. (1979) Isolation of synaptosomal fractions from rabbit retina, J. Neurosci. Methods 1, 235242.

41. Paul, A. K., Marala, R. B., Jaiswal, R. K., and Sharma, R. K. (1987) Coexistence of guanylate cyclase and atrial Natriuretic factor receptor in a 180-kD protein, Science 235, 1224-1226.

42. Nambi, P., Aiyar, N. V., and Sharma, R K. (1982) Adrenocorticotropin-dependent particulate guanylate cyclase in rat adrenal and adrenocortical carcinoma: Comparison of its properties with soluble guanylate cyclase and its relationship with ACTH-induced steroidogenesis, Arch. Biochem. Biophys. 217, 638-646.

43. Perrault, I., Rozet, J. M., Calvas, P., Gerber, S., Camuzat, A., Dollfus, H., Chatelin, S., Souied, E., Ghazi, I., Leowski, C., Bonnemaison, M., Le Paslier, D., Frezal, J., Dufier, J. L., Pittler, S., Munnich, A., and Kaplan, J. (1996) Retinal-specific guanylate cyclase gene mutations in Leber's congenital amaurosis, Nat. Genet. 14, 461-464.

44. Duda, T., Venkataraman, V., Goraczniak, R., Lange, C., Koch, K.-W., and Sharma, R. K. (1999) Functional consequences of a rod outer segment membrane guanylate cyclase (ROS-GC1) gene mutation linked with Leber's congenital amaurosis, Biochemistry $38,509-515$.

45. Kelsell, R. E., Gregory-Evans, K., Payne, A. M., Perrault, I., Kaplan, J., Yang, R. B., Garbers, D. L., Bird, A. C., Moore, A. T., and Hunt, D. M. (1998) Mutations in the retinal guanylate cyclase (RETGC-1) gene in dominant cone-rod dystrophy, Hum. Mol. Genet. 7, 1179-1184.

46. Buckley, K., and Kelly, R. B. (1985) Identification of a transmembrane glycoprotein specific for secretory vesicles of neural and endocrine cells, J. Cell Biol. 100, 1284-1294.

47. Rieke, F., and Schwartz, E. A. (1994) A cGMP-gated current can control exocytosis at cone synapses, Neuron 13, 863-873.

48. Savchenko, A., Barnes, S., and Kramer, R. H. (1997) Cyclicnucleotide-gated channels mediate synaptic feedback by nitric oxide, Nature 390, 694-698.

49. Krizaj, D., and Copenhagen, D. R. (2002) Calcium regulation in photoreceptors, Front Biosci. 7, d2023-d2044.

50. Koch, K.-W., Lambrecht, H. G., Haberecht, M., Redburn, D., and Schmidt, H. H. (1994) Functional coupling of $\mathrm{a} \mathrm{Ca}^{2+} /$ calmodulindependent nitric oxide synthase and a soluble guanylyl cyclase in vertebrate photoreceptor cells, EMBO J. 13, 3312-3320.

51. Fülle, H. J., Vassar, R., Foster, D. C., Yang, R. B., Axel, R., and Garbers, D. L. (1995) A receptor guanylyl cyclase expressed specifically in olfactory sensory neurons, Proc. Natl. Acad. Sci. U.S.A. 92, 3571-3575.

BI034025X 